\title{
La mujer oculta bajo el retrato de Jovellanos de Goya
}

\author{
Clara González-Fanjul, Araceli Gabaldón y Tamara Alba
}

\begin{abstract}
Resumen: La radiografía del primer retrato que Goya hizo de Gaspar Melchor de Jovellanos ha permitido conocer la existencia de una composición subyacente en la que está representada una mujer joven. Durante la primera fase del estudio de este documento, fue posible comprobar la concordancia de los rasgos pictóricos de los dos retratos, estableciéndose la posibilidad de que ambos fuesen obra del pintor aragonés. Así mismo, se observaron características en la indumentaria y en la posición de la mujer, que indicaron su pertenencia a la clase noble, lo que permitió situar la fecha de creación de esta pintura entre 1781 y 1785 . Sin embargo, no fue posible determinar la identidad de este personaje femenino, objetivo que ha condicionado la línea de investigación seguida posteriormente, cuyo desarrollo se expone de manera razonada en este artículo.
\end{abstract}

Palabras Clave: Goya; Radiografía; Pintura subyacente; Ma Teresa Vallabriga; Infante Don Luis.

\section{A mulher oculta no retrato de Jovellanos, de Goya}

Resumo: A radiografia do primeiro retrato feito por Goya de Gaspar Melchior de Jovellanos, permitiu desvendar a composição subjacente da representação de uma jovem mulher. Durante a primeira fase de estudo deste documento, foi possível comprovar a concordância entre as características pictóricas dos dois retratos, indiciando a possibilidade de que ambos sejam do mesmo artista aragonês. Além disso, observaram-se características na indumentária e na posição da mulher, que indicaram ter esta pertencido à nobreza, além de ter contribuído para delimitar a data de execução da pintura entre 1782 e 1785. Contudo, não foi possível determinar a sua identidade, o que condicionou a linha de investigação seguida, cujo desenvolvimento fundamentado aqui se expõe.

Palavras-chave: Goya; Radiografia; Pintura subjacente; Ma Teresa Vallabriga; Infante D. Luís.

\section{A woman hidden in the portrait Jovellanos, of Goya}

\begin{abstract}
The radiography of Goya's first portrait of Gaspar Melchor de Jovellanos has revealed the existence of a subjacent composition where a young woman is represented. During the first stage of the study of this document, the correspondence of the pictorial features of both portraits was verified and the possibility of both of them being painted by the Aragonese painter was established. In the same way, some characteristics in the attire and position of the woman were observed and showed she belonged to nobility. This set the date of creation of this painting between 1782 and 1785. However, the identity of this woman was impossible to determine, so the line of investigation followed has been conditioned, and this is what is reasoned in this article.
\end{abstract}

Keywords: Goya; Radiography; Underlying Painting; Ma Teresa Vallabriga; Infante Don Luis.

\section{Introducción}

En las proximidades del verano de 2010, a petición del Departamento de ConservaciónRestauración del Museo de Bellas Artes de Asturias, el Laboratorio de Estudios Físicos del Instituto del Patrimonio Cultural de España (IPCE) captó las imágenes radiográficas y reflectográficas de varias obras pertenecientes a dicho Museo. Entre ellas se encontraba el primer retrato que Goya hizo de Gaspar Melchor de Jovellanos [Figura 1], cuya radiografía evidenció la existencia de un re- 
trato femenino subyacente al del jurista, político y escritor asturiano. En este sentido, se debe señalar que la reutilización de lienzos ya pintados era un recurso frecuente en la metodología de trabajo de Francisco de Goya, que aprovechaba las capas de pintura secas de algunas composiciones como base para crear nuevas obras de manera rápida. El uso de este procedimiento ha sido constatado desde las etapas más tempranas de su producción, como puede ser el caso de El Bautismo de Cristo, fechada entre 1771 y 1780 (Torralba et al. 1986: 81; Gudiol 1979: I, 253 y II, 156; Gassier y Wilson 1970: 91), perteneciente a la colección de los Condes de Orgaz y realizada sobre un lienzo reutilizado en más de una ocasión. Así mismo, Garrochista (1791-1792) fue ejecutada encima de una figura ecuestre en la que algunos estudiosos han reconocido a Godoy. El retrato de la reina María Luisa de Parma (c. 1799) de la Colección Ibercaja, bajo el que hay una pintura de esta misma reina, pero vestida con una indumentaria distinta a la que se aprecia a simple vista y que, no obstante, guarda relación con el tipo de vestimenta plasmada por Goya unos diez años atrás (Calvo Serraller 2001: 246). Esta misma peculiaridad se da en obras tan conocidas como Isabel Lobo de Porcel (c. 1804-1805), de la Galería Nacional de Londres, pintada sobre un personaje masculino; el retrato de la Condesa de Chinchón (1800) expuesto en el Museo del Prado, que fue plasmado sobre dos retratos sucesivos' (Mena 2008: 188-190; Mena y Maurer 2006: 102-103; Garrido 2003: 45-47), el retrato de una Dama, también del Museo del Prado, o el del Duque de Wellington (1812), debajo del cual, hay otro retrato ecuestre ${ }^{2}$ (Gassier y Wilson 1970: 262).

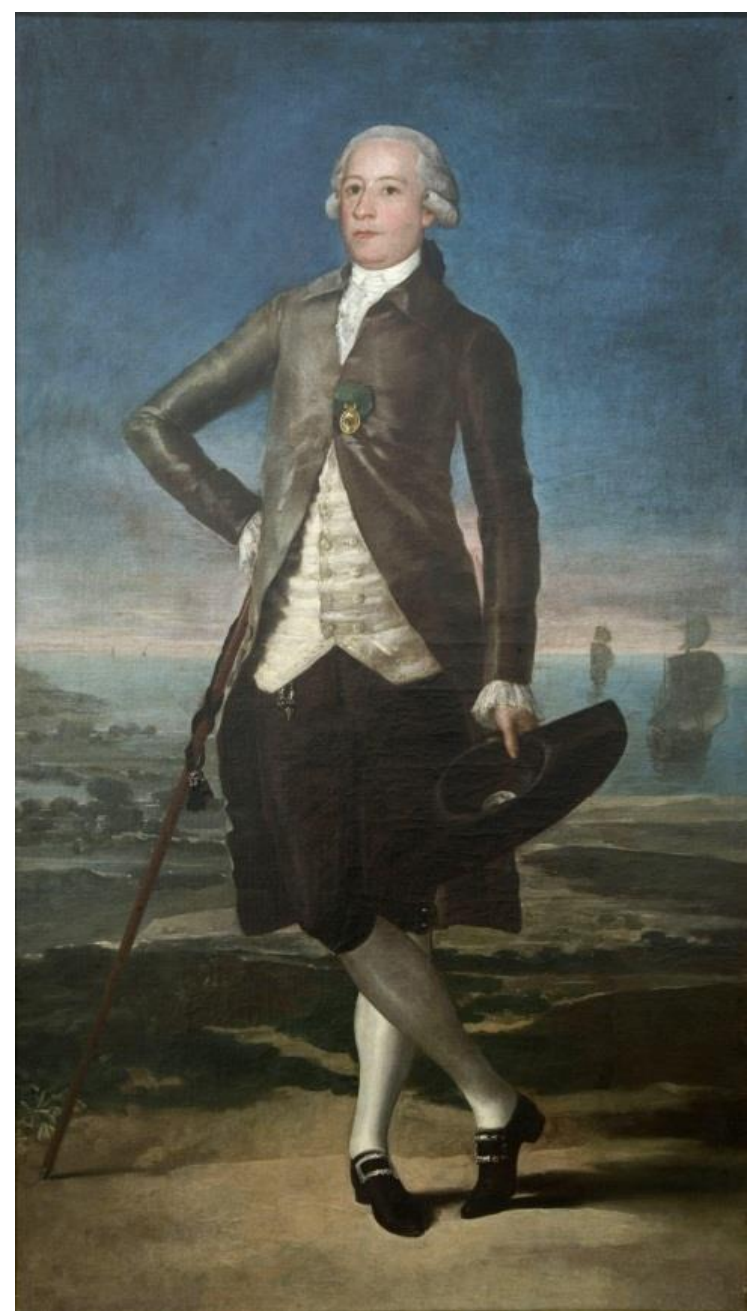

Figura 1. Imagen visible del primer retrato que Goya hizo de Gaspar Melchor de Jovellanos (1784-1785). Museo de Bellas Artes de Asturias. 
La interesante contribución que podía constituir la radiografía del retrato de Jovellanos para el conocimiento técnico y artístico de la obra de Goya llevó a profundizar, en el análisis e interpretación de los datos contenidos en ella ${ }^{3}$. La primera fase de esta investigación fue publicada en el año 2011 (González-Fanjul, Gabaldón et Alba 2011: 159-173) tras su presentación en las Jornadas de Ciencia y Arte III, que se celebraron en Valencia en noviembre de 2010, organizadas por el Instituto del Patrimonio Cultural de España en colaboración con el Institut Valencià de Conservació i Restauració de Bens Culturals. Durante el desarrollo de esta etapa del estudio se analizaron los rasgos pictóricos tanto del retrato de Jovellanos como de la composición subyacente y, posteriormente, se procedió a la comparación de estas características con el objetivo de establecer similitudes, y discordancias en la factura de ambos, de manera que fuese posible comprobar si la pintura femenina también podía ser obra de Goya. Por otro lado, la gran incógnita que suponían la identidad de la mujer $y$, por ende, la fecha en la que fue retratada, motivaron el estudio de su indumentaria en el contexto de la evolución de la moda textil femenina, así como la búsqueda de parecidos entre la fisionomía de su rostro y las facciones de otras mujeres pintadas por Goya. De este modo, fue posible saber que el retrato femenino fue pintado con rapidez, posiblemente, partiendo de un estudio previo, ya que no se ha detectado ningún arrepentimiento ni vacilación o corrección de los trazos. Así mismo, se pudo comprobar que el tipo de pincelada coincidía en los dos retratos, al igual que otras características propias de la técnica del pintor aragonés, como puede ser la delimitación de las figuras mediante una línea que sigue el recorrido de su contorno, o la aplicación de pinceladas cortas, rápidas y decididas. Todo ello permitió establecer la posibilidad de que ambos retratos hubiesen sido realizados por la misma mano.

Con respecto a la joven y su identidad, gracias a la radiografía [Figura 2] fue posible saber que está representada de cuerpo entero, de pie y con su mano izquierda apoyada sobre lo que parece ser una mesa, símbolo de conocimiento, riqueza y poder, que solía ser reservado para retratar a miembros de la nobleza. Viste un traje largo que llega al suelo, provisto de un cuerpo ajustado y una falda interior o brial revestida con una sobrefalda abierta por delante. El cuerpo del vestido tiene manga tres cuartos terminada en volantes y está dotado de un amplio escote cubierto con muselina ahuecada. En el centro de este escote se observa un pico ribeteado con un volante fruncido y una lazada. La parte baja de la falda está adornada también con un volante de una tela que parece similar a la del escote, mientras que las caídas laterales de la sobrefalda están decoradas con encajes, lazos, cintas y flores. Estas características fueron cotejadas con las de los ropajes que aparecen en los retratos de otras mujeres de finales del siglo XVIII, siendo posible comprobar las coincidencias existentes con el robé a l'anglaise o baquero azul que viste la Marquesa de Benavente en el retrato que le hizo Goya en 1785, actualmente perteneciente a la Colección particular de los herederos de Bartolomé March de Palma de Mallorca. No obstante, la presencia del lazo en la parte central del escote es propia de otro vestido denominado polonesa, razón por la que durante esta fase del estudio no fue descartada esta posibilidad. Otro detalle que se debe señalar en relación a la pose y a la indumentaria de la mujer del retrato subyacente al de Jovellanos, es que se muestra al espectador uno de sus tobillos y un zapato de forma puntiaguda, también llamado chinela, hecho que se hacía en representación de la elegancia y la limpieza. En su mano izquierda lleva una pulserita de tela o joyel de la que se solía colgar un retrato del ser querido, muy de moda en esa época. En cambio, en la derecha permanece colgado un pequeño bolso acompañado de un objeto circular que no se ha podido distinguir correctamente, debido a que su localización en la imagen radiográfica se superpone a la del travesaño del bastidor.

En cualquier caso, la vestimenta es lujosa, sus elementos son propios de la moda que se introdujo en España hacia 1782 y, en lo que respecta al baquero o robé a l'anglaise, dejó de ser tendencia en 1785. Esto implica que el retrato femenino no pudo ser realizado con anterioridad ni posterioridad al intervalo de tiempo comprendido entre esos años, al igual que indica la pertenencia de la mujer 
a la nobleza, puesto que la moda estuvo reservada a las clases altas hasta el siglo XIX por su elevado coste. Al hilo de esta cuestión, cabe destacar que sobre el peinado de la joven hay un tocado de rosas con una mantilla, cuyo uso se impuso en torno a 1780 entre las mujeres nobles y de la alta burguesía, si bien el tocado dejó de estar de moda en 1785. Tanto el tocado como la mantilla, guardan gran similitud con los que lleva en su retrato María Teresa de Borbón pintada por Goya en 1783 cuando era niña, cuya boca y ojos se parecen a los de la mujer objeto de este estudio. La relación cronológica detallada previamente, permitió situar la creación del retrato femenino entre 1782 y 1785, hipótesis que resultó reforzada por el hecho de que Goya comenzó a tener contacto con la clase noble en 1780, sumado a que durante el siguiente año estuvo trabajando en Zaragoza y hasta 1782, no regresó a Madrid. Sin embargo, no fue posible determinar la identidad de la mujer del retrato subyacente, a pesar de cotejar sus rasgos faciales con los de varias mujeres pintadas por Goya, dado que, si bien se habían observado concordancias entre algunas de ellas, las edades que tenían en el momento de la ejecución del subyacente no coincidían. Precisamente, ésta es la finalidad del presente artículo, que se ha centrado en la comparación de la desconocida mujer con otras retratadas, contrastando la información con documentos escritos que contribuyen a corroborar la teoría planteada.

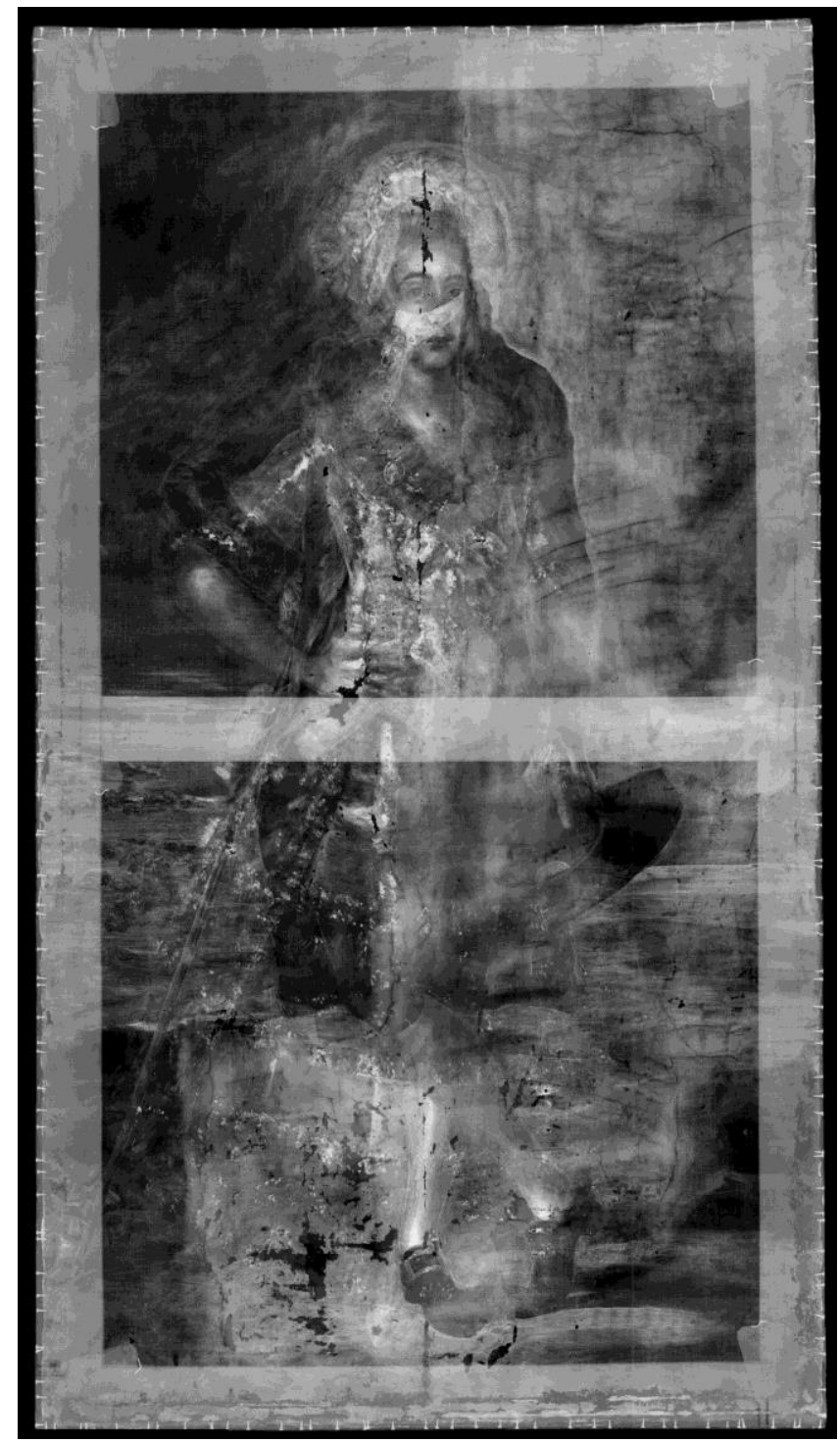

Figura 2. Imagen radiográfica del retrato Jovellanos pintado por Goya entre 1784-1785. Instituto del Patrimonio Cultural de España (IPCE). 


\section{El retrato subyacente: interpretación del personaje}

Durante la primera etapa de la investigación, las facciones del rostro de la dama oculta tras Jovellanos fueron comparadas con las de la Marquesa de Santa Cruz [Figura 3], de modo que se pudieron observar las semejanzas que había entre ambas, si bien se descartó esta opción, debido a que la Marquesa fue retratada unos veinte años después (1805), cuando aún era joven. Así mismo, fue posible comprobar las concordancias existentes entre los ojos y la boca de la mujer del retrato subyacente en el que se centra este estudio y los de $M^{a}$ Teresa de Borbón cuando fue pintada por Goya siendo niña (1783). La fecha de ejecución de esta última obra, evidenció que no se podía tratar de la misma persona. No obstante, dada la coincidencia cronológica de la creación de estos dos retratos, unida al parecido de las mantillas y de los tocados de la hija del Infante Don Luis con los de la mujer oculta tras Jovellanos, estos elementos fueron tomados como referencia visual de la indumentaria de esta última.

Desde el momento en que fue difundida la imagen radiográfica del retrato del ilustrado gijonés, junto con los primeros resultados obtenidos de su estudio, se recibieron varias propuestas de identidades que podrían corresponder a la joven de la composición subyacente. Entre ellas, cabe señalar a "Enarda"4, el gran amor sevillano de Jovellanos, así como a la Marquesa de Villafranca, madre del supuesto hijo del jurista, político y escritor, o el de María Teresa de Vallabriga, esposa del Infante Don Luis Antonio de Borbón ${ }^{5}$, pintada por el aragonés en diversas ocasiones.

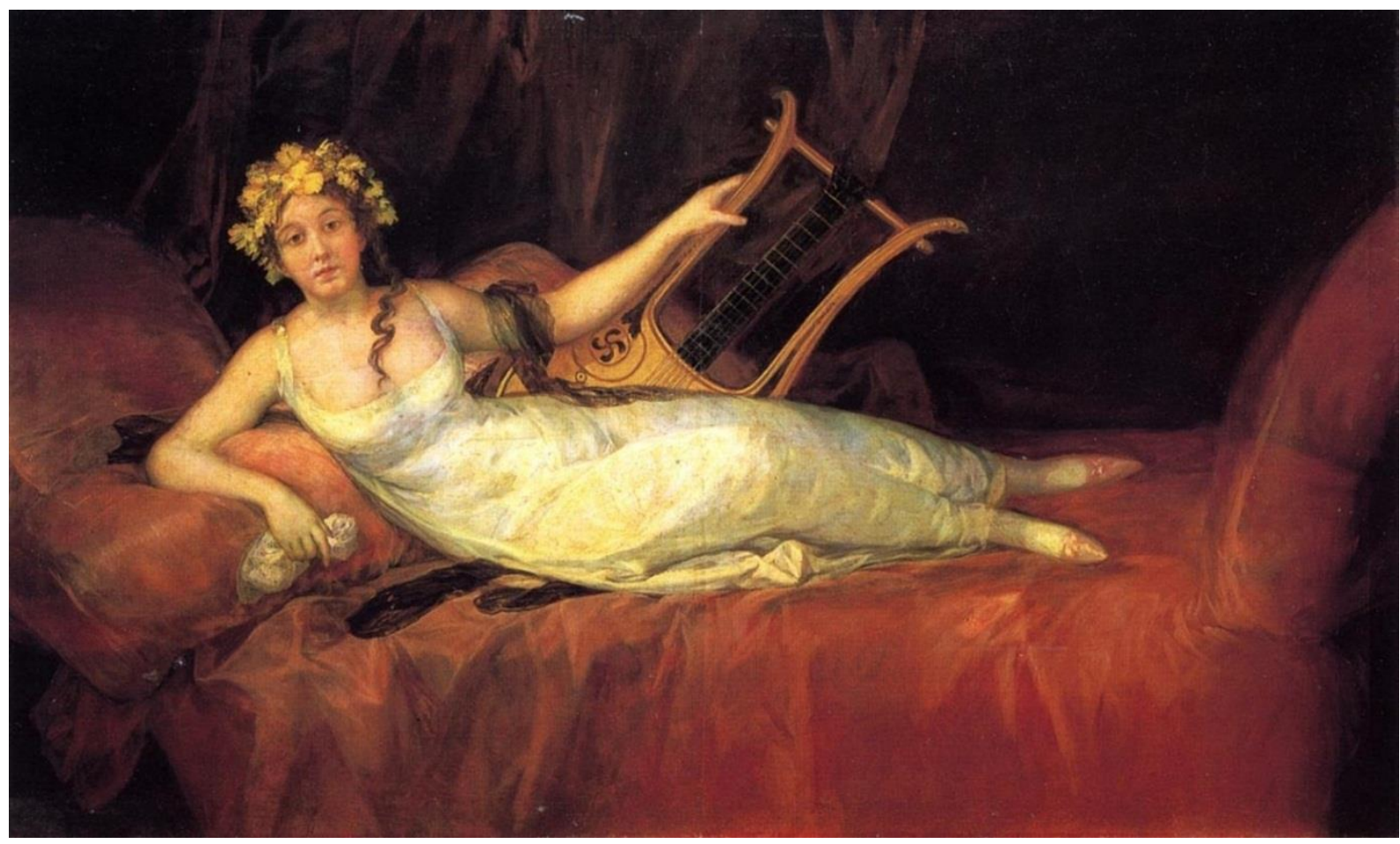

Figura 3. Retrato de Marquesa de Santa Cruz, pintado por Goya en 1805. Museo del Prado.

Como consecuencia de los fuertes vínculos que relacionaban a esta última candidata con Goya y con $\mathrm{M}^{\mathrm{a}}$ Teresa de Borbón [Figura 4], el hilo de la investigación se concentró en comprobar la posible identificación de $M^{a}$ Teresa de Vallabriga como la joven sobre cuyo retrato se pintó el de Gaspar 
Melchor de Jovellanos. En este sentido, se profundizó en el conocimiento de la vida de esta mujer y de la familia que formó al lado del Infante Don Luis, así como en los avatares de sus miembros y en los lazos que les unían a Francisco de Goya y Lucientes. Paralelamente, se efectuó un nuevo examen de los rasgos de la joven del retrato subyacente, que en esta ocasión fueron comparados con los de la esposa del Infante, tomando como principales modelos dos retratos que Goya hizo a esta última en 1783. Uno de ellos pertenece actualmente a la Colección Pérez Simón [Figura 5], mientras que el otro se conserva en la Pinacoteca Antigua de Munich [Figura 6].

$M^{a}$ Teresa de Vallabriga nació en Zaragoza el 6 de Noviembre de 1759. Era hija de José de Vallabriga y Español, Teniente Coronel del Regimiento de Voluntarios a Caballo y de Da Josefa de Rozas y Drumond, Condesa viuda de Torresecas (Ansón 1995: 269). A la edad de 13 ó 14 años quedó huérfana, por lo que sus tíos, los Marqueses de San Leonardo, se ocuparon de su cuidado y educación en Madrid. Su tío era caballerizo de Carlos III, motivo por el que eran frecuentes las visitas de la familia a la Granja de San Ildefonso, donde $M^{a}$ Teresa conoció al hermano menor del Rey, el Infante Don Luis.

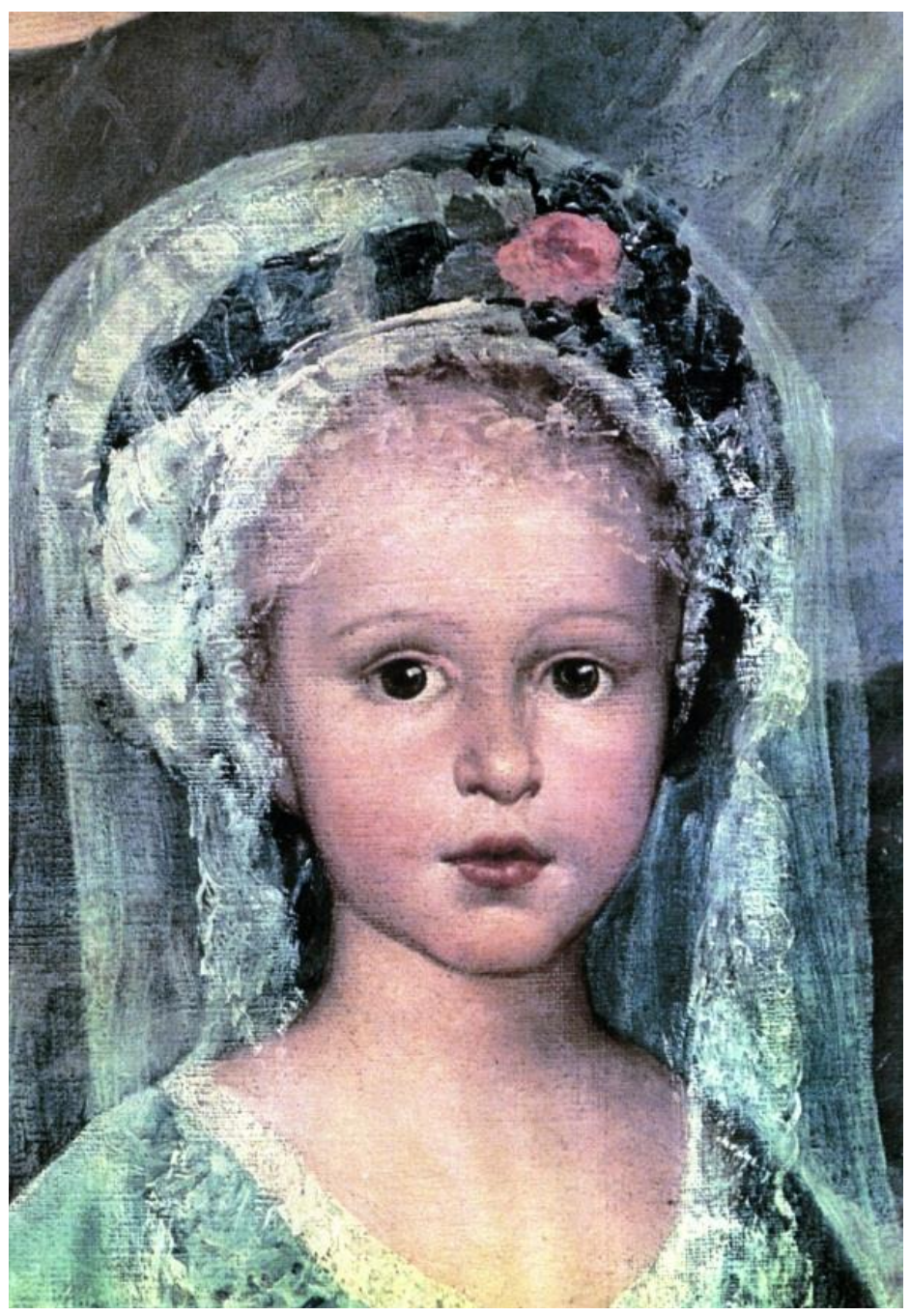

Figura 4. Detalle del rostro, el tocado y la mantilla de María Teresa de Borbón y Vallabriga en el retrato que le hizo Goya en 1783. National Gallery de Washington. 


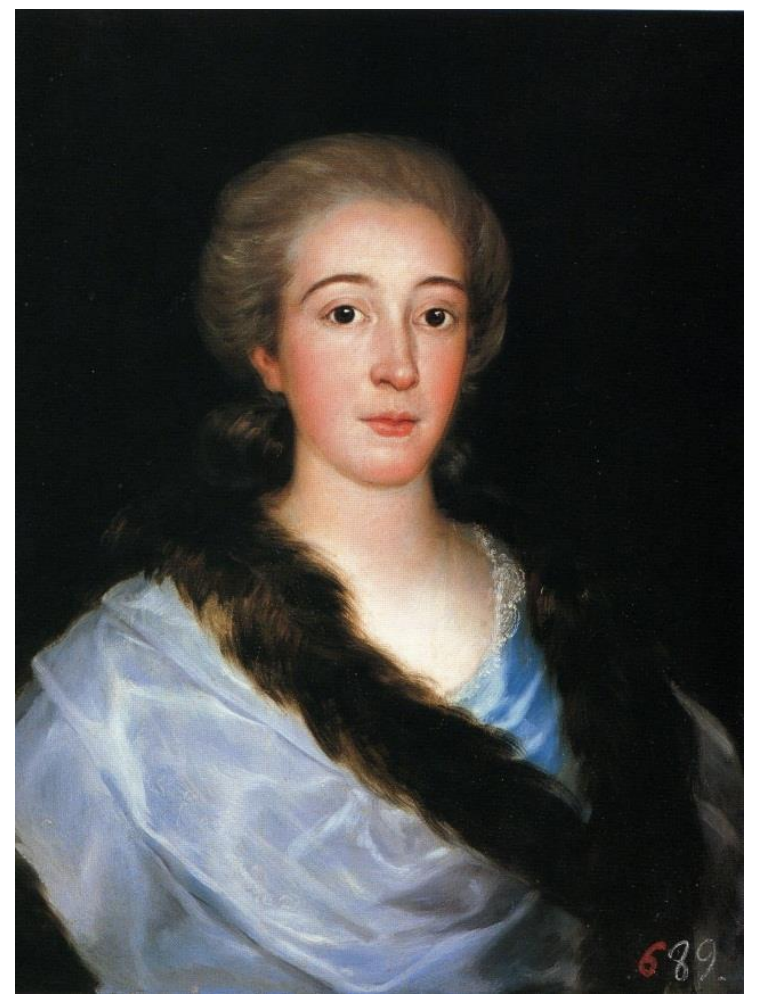

Figura 5. Retrato de Ma Teresa de Vallabriga. Goya, 1783. Colección “Pérez Simón” (Méjico).

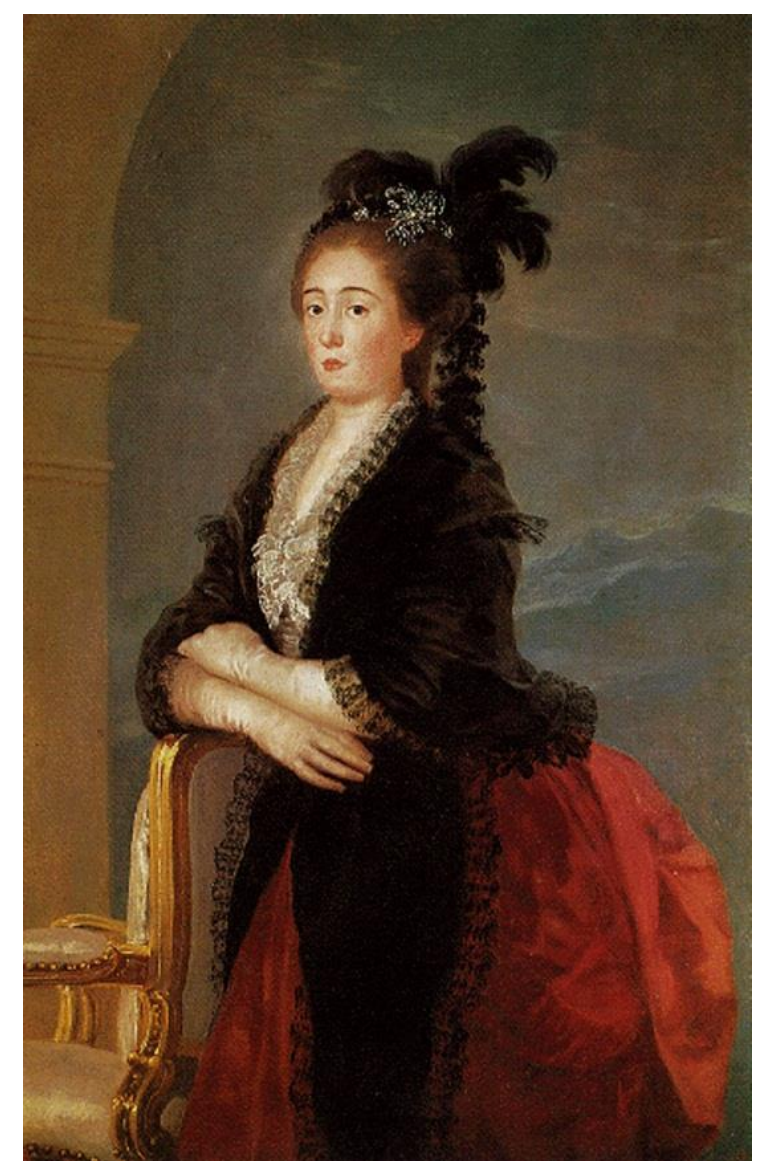

Figura 6. Retrato de Ma Teresa de Vallabriga. Goya, 1783. Pinacoteca Antigua de Munich. 
Según la Ley sálica vigente en aquella época, el nacimiento y crianza en España era uno de los requisitos que se exigía para que los Infantes accedieran al trono. A este respecto, el hijo de Carlos III, aquel que posteriormente se convirtió en Carlos IV, había nacido y se había educado en Nápoles, por lo que su propio tío, el Infante Don Luis y los descendientes de éste, si los tenía, gozaban de preferencia en la línea de sucesión. Esta fue la causa de que el Rey mandara publicar una pragmática sanción dirigida a los matrimonios de desigual condición, tales como los que se podían dar entre nobles y personas de diferente posición social. Esta norma excluía de la sucesión al trono a los hijos nacidos de estos enlaces e incluso, se dictaminó que los esposos y sus hijos vivieran fuera de la Corte. Para asegurar la posición de su heredero, Carlos III impulsó el matrimonio entre su hermano y $\mathrm{M}^{\mathrm{a}}$ Teresa de Vallabriga, que tuvo lugar en junio de 1776 mediante una ceremonia sencilla a la que no acudieron los miembros de la familia real.

Desde entonces, los nuevos esposos tuvieron prohibido acercarse a la Corte a menos de veinte leguas. Dada la situación, decidieron instalarse provisionalmente en el Palacio que los Marqueses de Altamira tenían en Velada, para acabar asentándose en el Palacio que el Infante Don Luis había mandado construir a Ventura Rodríguez en Arenas de San Pedro -Avila-. La vida de la pareja era tranquila y acomodada, pero también aburrida y monótona, con la única distracción de la naturaleza de su entorno y la compañía de sus cortesanos, las visitas de Goya y de Boccherini. A todo ello, se debe añadir que estaban obligados a recibir a personas impuestas desde Madrid, como pueden ser D. Miguel de Aristía, Consejero del Rey, o fray Urbano de los Arcos, confesor de Don Luis. Ambos emisarios mantenían correspondencia con Floridablanca, el Secretario del Rey, en la que informaban de la actividad del matrimonio y denunciaban que $M^{a}$ Teresa maltrataba y humillaba públicamente a su esposo quien, débil de carácter y ya enfermo, se dejaba manejar e intimidar por ella. No obstante, fueron padres de cuatro hijos de los cuales sobrevivieron tres: Luis $\mathrm{M}^{\mathrm{a}}$, $\mathrm{M}^{\mathrm{a}}$ Teresa y $\mathrm{M}^{\mathrm{a}} \mathrm{Lui}$ sa.

La relación de Goya con la familia del Infante Don Luis comenzó cuando éstos fueron presentados por el arquitecto Ventura Rodríguez. Según se desprende de una carta escrita por el pintor a su hijo con fecha de septiembre de 1783 (Goya 1981: 250), Francisco de Goya pasó un mes en el Palacio de Arenas de San Pedro invitado por el Infante, con la finalidad de hacer varios retratos de su familia. En la misma, el pintor indica el buen trato que mantuvo con Don Luis, con quien fue de caza y de quien recibió distintos regalos, hasta el punto de que la invitación fue reiterada para los siguientes años:

"1783. IX.20

Madrid

Querido hijo mío: Acabo de llegar de Arenas y muy cansado. Su Alteza me a echo mil onores; he echo su retrato, el de su señora y niño y niña con un aplauso inesperado por aber hido ya otros pintores y no aber acertado a esto... He hestado un mes continuamente con estos señores y son unos ángeles. Me an regalado mil duros y una bata para mi muger, toda de plata y oro que bale treinta mil reales, según me dijeron allí los guarda ropas; $y$ an sentido tanto que me aya hido que no se podían despedir del sentimiento, y con las condiciones que abía de volver lo menos todos los años..."

A juzgar por la existencia de otros retratos posteriores de la familia del Infante y, sobre todo, de su esposa, está claro que el pintor aceptó dicha invitación con agrado. En otra carta de julio de 1784 (Goya 1981: 254), Goya escribe a su amigo Martín Zapater comunicándole que se encuentra en Arenas de San Pedro trabajando en el retrato ecuestre de $M^{a}$ Teresa de Vallabriga, cuyo boceto se conserva actualmente en los Ufizzi de Florencia: 
"1784.VII.2

Arenas de San Pedro

Querido Martín. Estoy flaco y no trabajo mucho. Aun no he acabado el retrato a caballo de la Señora del Infante, pero le falta poco...".

Cabe la posibilidad de que esta última estancia en Arenas se alargara por unos meses, aunque tampoco se debe descartar que el pintor hiciera varios viajes sucesivos para cumplir diferentes encargos del Infante. En esta otra carta, nuevamente dirigida a Zapater, pero escrita ya desde Madrid (Goya 1981: 255-256), Goya le informa de que ha estado pintando para el Infante Don Luis:

"1784. X.13

Madrid

Querido Martín mío: Ciertamente que acía ya mucho tiempo que nada sabíamos el huno del otro. Yo he estado sirviendo al serenísimo Señor Infante don Luis. Sería muy largo el decirte las satisfacciones que le he merecido...

De los intereses me ba muy bien. El Infante me dio treinta mil reales en gratificación de dos cuadros que le he pintado...

Francisco de Goya".

Haciendo referencia al cuadro La familia del Infante Don Luis, que se encuentra en la Fondazione Magnani-Rocca de Parma, Junquera y Mato especifica que el lienzo original fue pintado en 1784, durante la segunda estancia de Goya en Arenas de San Pedro y señala que los 30.000 reales que recibió del Infante se debían al pago por la ejecución del retrato ecuestre de doña María Teresa, así como de esta composición en la que aparece toda la familia (Junquera y Mato et Patio de la Infanta 1996: 126). Esta última obra [Figura 7] ofrece una escena en cuyo centro se sitúa el Infante, de perfil y con la mirada perdida. A su lado se encuentra $M^{a}$ Teresa de Vallabriga, a la que están peinando para ser retratada por Goya, quien está ubicado en la parte izquierda de la composición, junto al caballete, de espaldas al espectador, pero con el rostro ladeado. Próximos a él, están de pie los dos hijos mayores del matrimonio - $M^{a}$ Teresa y Don Luis $M^{a}$ de Borbón- acompañados de sus ayas Doña Antonia de Vanderbrocht y Doña Petronia Valdearenas-. Una de ellas sostiene una bandeja sobre la que están depositados los aderezos que componen el tocado que el peluquero personal de la esposa del Infante le va a colocar a ésta. Todos estos tocados se asemejan entre sí, al igual que el de Doña Isidra Fuentes y Michel, quien lleva en brazos a la pequeña $M^{a}$ Luisa de Borbón y Vallabriga (Junquera y Mato 1996: 126-129; Valverde 1989: 793-802). El interés de esta obra radica no sólo en que aparecen retratados todos los miembros de la familia, junto a Goya y a otras personas, sino, sobre todo, en que los tocados y algunos elementos de la vestimenta de $\mathrm{M}^{\mathrm{a}}$ Teresa, como pueden ser la cenefa que adorna la parte baja de la falda y los zapatos, coinciden con los que se observan en la radiografía del retrato de Jovellanos.

Siendo pequeños los niños, en el verano de 1785, el Infante Don Luis sufrió una enfermedad que acabó con su vida y supuso un gran cambio para toda la familia. Por orden del Rey, a partir de ese momento, $\mathrm{M}^{\mathrm{a}}$ Teresa de Vallabriga podría usar el título de Condesa de Chinchón ${ }^{6}$, pero se le prohibió volver a su tierra natal -Zaragoza- y tampoco se le permitió visitar a sus hijos, quienes fueron educados por Don Francisco de Lorenzana, Arzobispo Primado de Toledo. De esta manera, la que había sido esposa del Infante Don Luis se quedó sola y prácticamente confinada en su Palacio de Arenas de San Pedro hasta la muerte de Carlos III en 1792. Su sucesor, Carlos IV, revocó las condiciones impuestas a $\mathrm{M}^{\mathrm{a}}$ Teresa de Vallabriga, otorgándole libertad de establecimiento en cualquier lugar. Gracias a ello, la Condesa se instaló en su ciudad natal y residió en el Palacio de Zaporta hasta que estalló la Guerra de la Independencia (1808), que motivó su traslado a Mallorca. En 1797 se restablecen sus derechos y los de sus hijos en las capitulaciones matrimoniales de su hija mayor, $\mathrm{M}^{\mathrm{a}}$ 
Teresa de Borbón, con Manuel Godoy. Ma Teresa de Vallabriga, la llamada Infanta viuda, regresó a Zaragoza en 1814, viviendo allí hasta su fallecimiento en 1820.

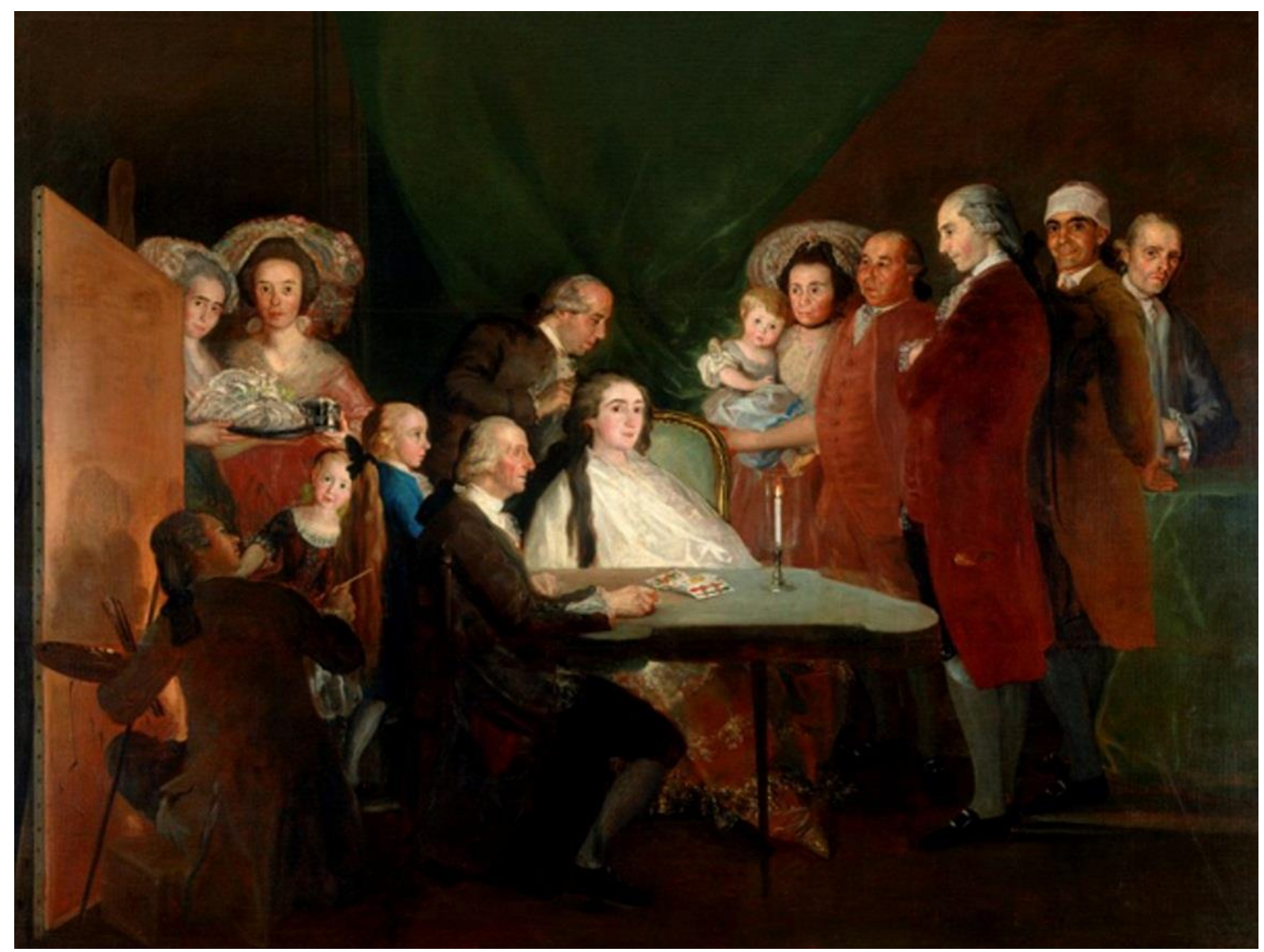

Figura 7. La familia del Infante Don Luis. Goya, 1784. Fondazione Magnani-Rocca, Parma.

En referencia a la comparación de los rasgos de la mujer del retrato subyacente al de Jovellanos con los de $M^{a}$ Teresa de Vallabriga en dos de los cuadros que Goya pintó de ella en 1783, se debe señalar que el conservado en la Pinacoteca Antigua de Munich, ha permitido reconocer el gran parecido existente entre ambas mujeres [Figura 8]. Las coincidencias de su rostro, han podido ser constatadas mediante la superposición de las características faciales de $\mathrm{M}^{\mathrm{a}}$ Teresa en el cuadro de la Colección mejicana "Pérez Simón" y las de la mujer de la radiografía. Gracias a este método, fue posible observar las concordancias existentes en las facciones alargadas, las narices y las barbillas prominentes de ambas mujeres, al igual que en la factura de sus bocas, las cejas redondeadas, los ojos de expresión despierta, aunque con una mirada profunda y distante [Figuras 9 y 10]. Un dato curioso a este respecto es que, a diferencia del retrato subyacente al de Jovellanos, cuyos trazos están aplicados sin vacilación ni corrección alguna, durante el análisis técnico efectuado en el Museo del Prado en 1992 al retrato de la Colección mejicana fueron detectados tanto un dibujo previo en la zona de los ojos de $\mathrm{M}^{\mathrm{a}}$ Teresa de Vallabriga, como varios arrepentimientos (Calvo Serraller et al. 2001: 176-177). Sin embargo, lo más destacado y relevante de este análisis para el estudio que aquí se describe, es que en la obra que pertenece a la Colección de Pérez Simón, la esposa del Infante Don Luis había sido representada inicialmente con un traje similar al que luce la Condesa de Benavente en el retrato que Goya le hizo en 1785 , aunque la indumentaria quedó oculta bajo la 
elegante manteleta en el estado final de la pintura. Independientemente de las razones por las que se llevó a cabo esta acción, el hecho es que el traje con el que $M^{a}$ Teresa fue retratada originalmente era un robé a l'anglaise, igual que la mujer oculta bajo Jovellanos.

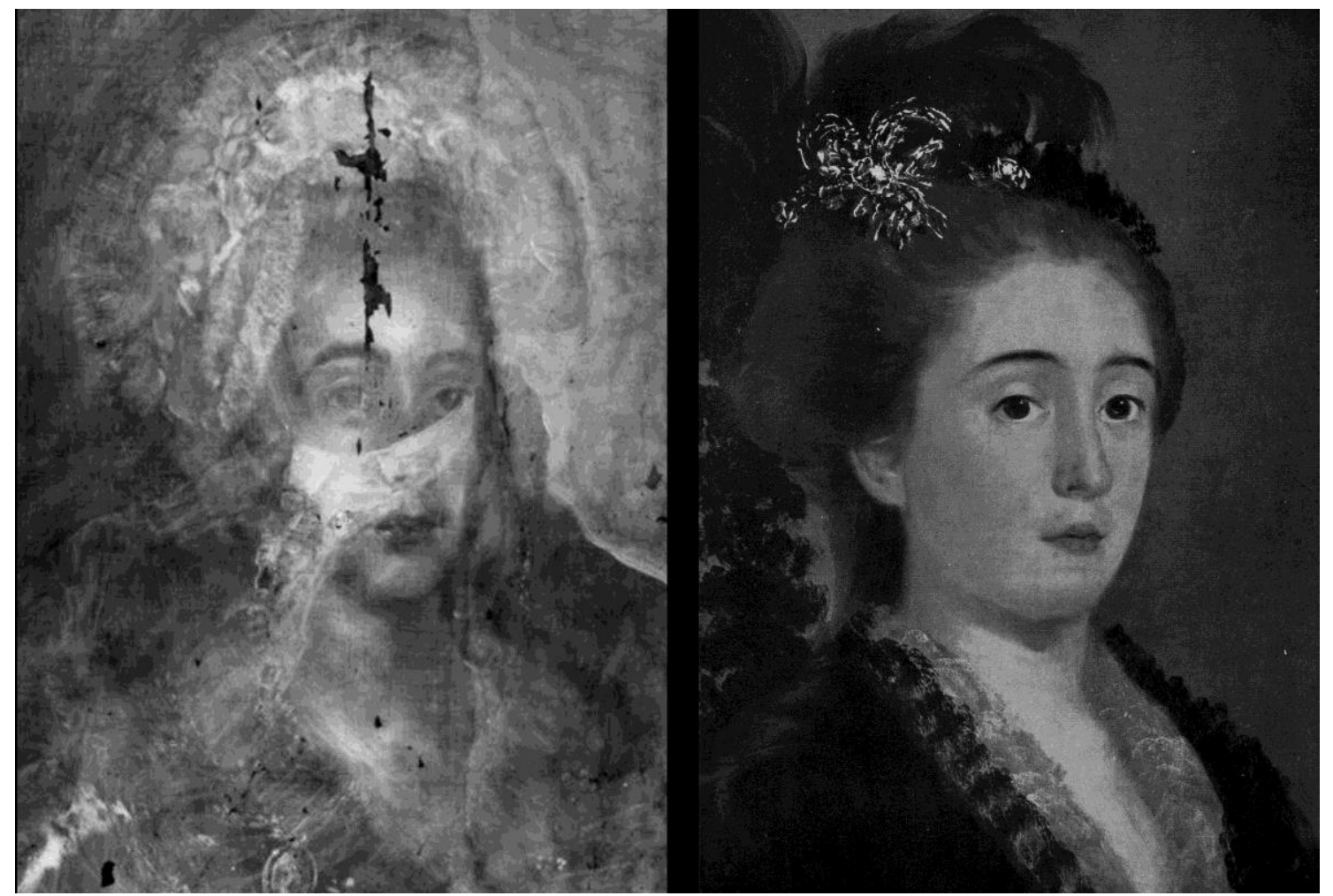

Figura 8. Detalle del rostro de la mujer desconocida en la imagen radiográfica del retrato de Jovellanos, junto al retrato de $M^{a}$ Teresa de Vallabriga que le hizo Goya en 1783, conservado en la Pinacoteca Antigua de Munich.

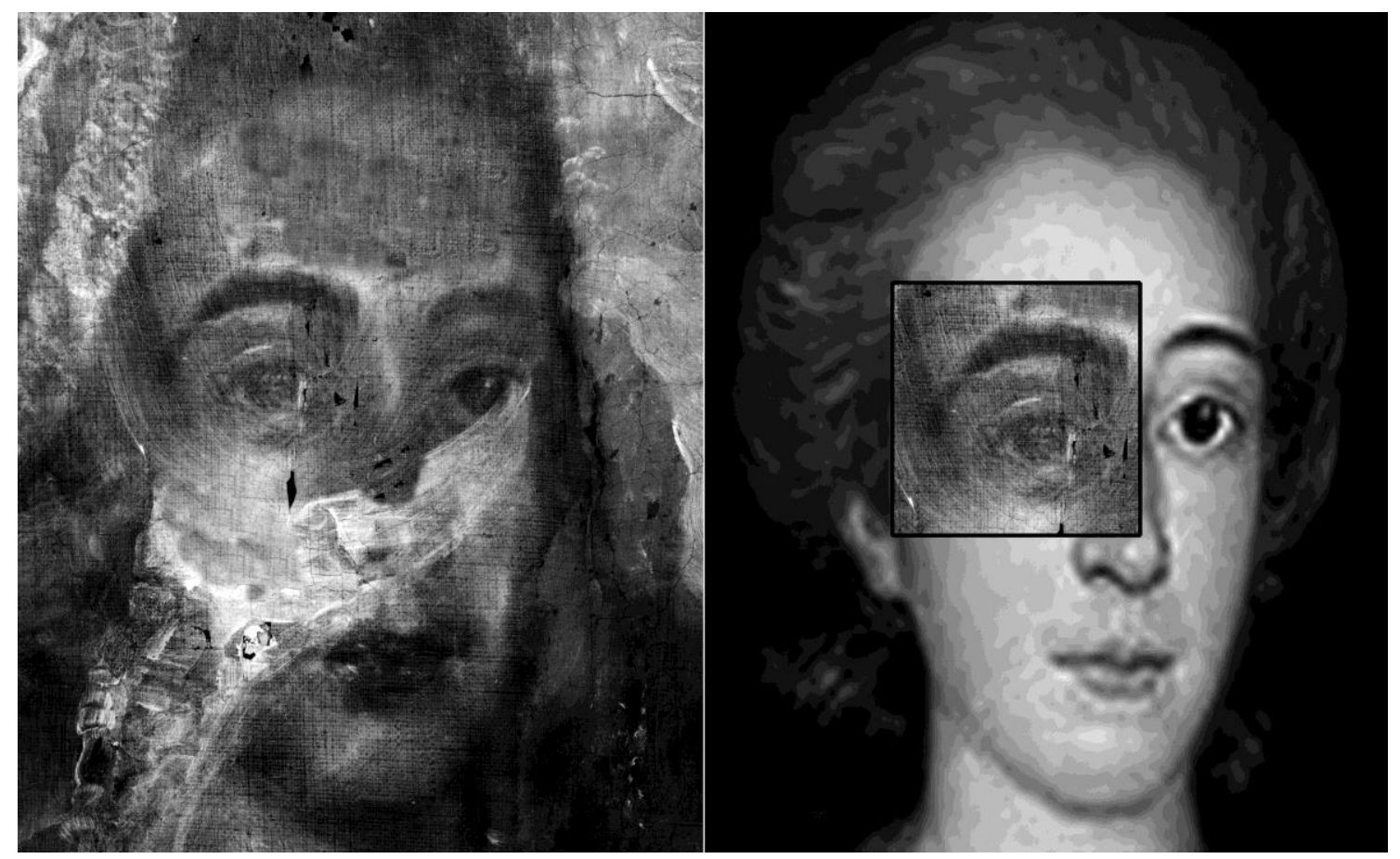

Figura 9. Rasgos faciales de la mujer del retrato subyacente al del ilustrado gijonés, superpuestos al retrato de $M^{a}$ Teresa de Vallabriga de la Colección "Pérez Simón". 


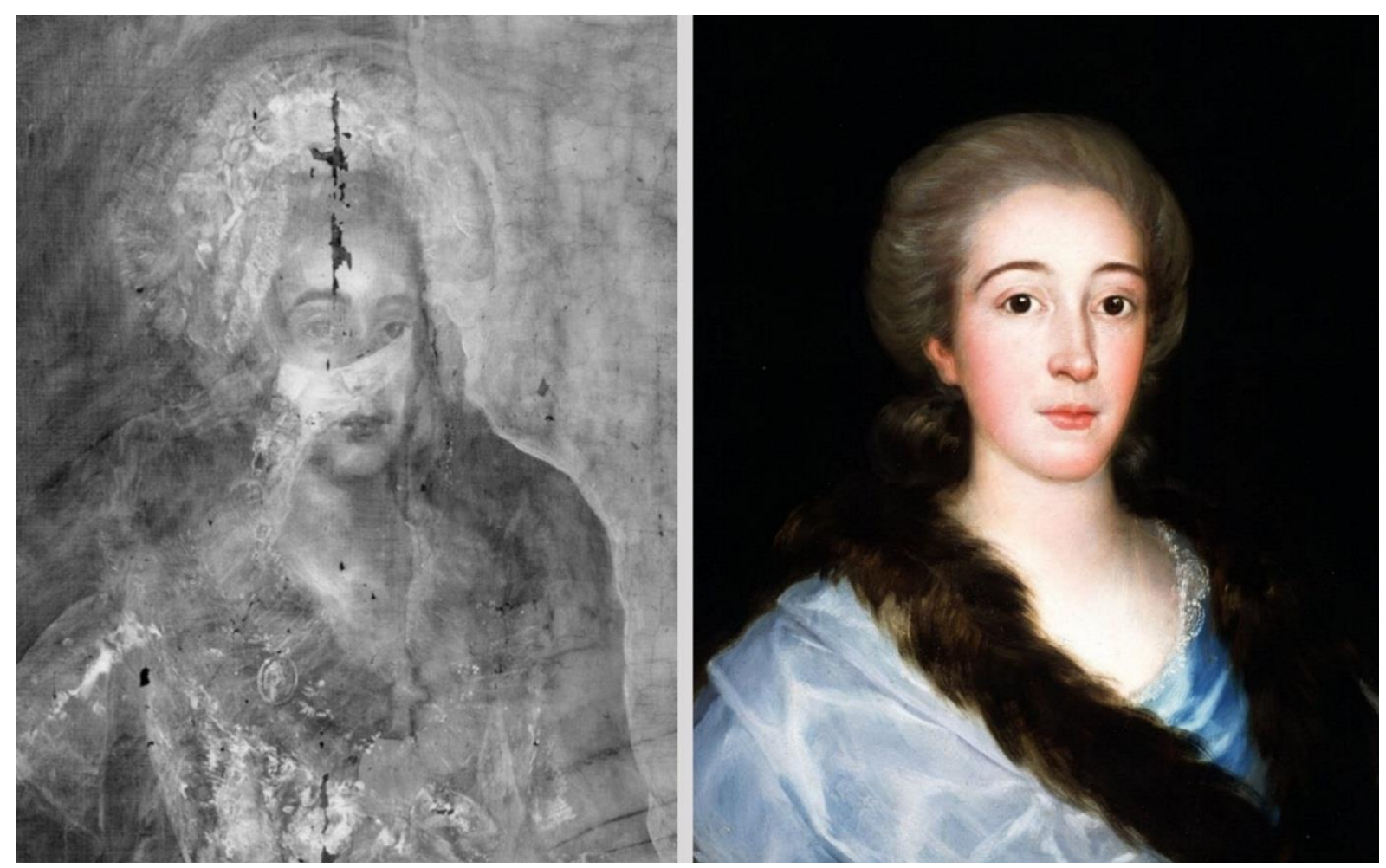

Figura 10. Detalle de la cabeza y el pecho de la figura femenina representada en la composición que subyace a la de Jovellanos, junto al retrato de Ma Teresa de Vallabriga, perteneciente a la Colección "Pérez Simón".

\section{Conclusiones}

Mediante el estudio de la imagen radiográfica del primer retrato que Goya pintó de Gaspar Melchor de Jovellanos, ha sido posible conocer la existencia de otra composición subyacente en la que se representa a una mujer. Igualmente, se han obtenido resultados y se han establecido conclusiones acerca del momento cronológico en el que fue realizado el retrato subyacente, la posible autoría de éste y la identidad de la joven representada.

En este sentido, se detectaron concordancias en la técnica de ejecución de los dos retratos, tales como el tipo de pincelada -corta, rápida y decidida-y la delimitación de las figuras haciendo uso de una línea que sigue su contorno. Estas características, unidas al uso del recurso de pintar sobre obras realizadas previamente, señalan la posibilidad de que Goya fuese también el artífice del retrato femenino.

Con respecto a la identidad de la retratada, durante la fase inicial de esta investigación fue posible saber que era una persona perteneciente a la nobleza. Indicio de ello es el hecho de que la joven está apoyada sobre una mesa, como símbolo de conocimiento y poder, pero, sobre todo, se debe destacar su indumentaria adecuada a la moda seguida a principios de la década de los 80 del siglo XVIII, cuyo elevado coste únicamente estaba al alcance de los miembros de la nobleza y de la alta burguesía. No obstante, no fue posible relacionar su rostro con ningún nombre propio. Al hilo de esta cuestión, ha sido durante esta segunda etapa del estudio cuando se han podido conocer di- 
versos datos y circunstancias coincidentes, que indican a $\mathrm{M}^{\mathrm{a}}$ Teresa de Vallabriga como la persona que, con gran probabilidad, se representa en este retrato.

Esta hipótesis ha adquirido sentido al tener en cuenta los nexos existentes entre la mujer del retrato subyacente, $M^{a}$ Teresa de Borbón, el Infante Don Luis Antonio de Borbón, $M^{\mathrm{a}}$ Teresa de Vallabriga y Francisco de Goya. El primero de los hechos que vincula a estas personas es que todas ellas fueron retratadas en algún momento de su vida por el pintor aragonés. Por otra parte, $M^{a}$ Teresa de Vallabriga era la esposa del Infante Don Luis, con quien tuvo varios hijos, entre los que se encontraba $\mathrm{M}^{\mathrm{a}}$ Teresa de Borbón, la niña cuyos ojos, boca, tocado y mantilla, guardan gran parecido con los de la joven desconocida de la composición subyacente a la de Jovellanos. En cuanto a la relación de $\mathrm{M}^{\mathrm{a}}$ Teresa de Vallabriga con la mujer cuya identidad se pretendía conocer, la primera coincidencia que se da es que ambas eran jóvenes en los primeros años de la década de los 80 del siglo XVIII, pues esa es la época en la que se ha situado la creación del retrato subyacente y Ma Teresa de Vallabriga nació en 1759. Además, fue posible reconocer la similitud de sus rasgos gracias al retrato que se conserva de la esposa del Infante en la Pinacoteca Antigua de Munich. En este contexto, la superposición de las facciones de $M^{a}$ Teresa de Vallabriga, en el retrato que actualmente pertenece a la Colección "Pérez Simón", con las de la mujer de la composición subyacente a la de Jovellanos, fue determinante para comprobar la correspondencia entre la factura de sus narices y barbillas prominentes, su boca, sus cejas redondeadas y sus ojos despiertos con los que, sin embargo, ambas miran de manera profunda y distante. A todo ello, se de añadir que tanto la joven de identidad desconocida, como $\mathrm{M}^{\mathrm{a}}$ Teresa de Vallabriga en el estado original del retrato de la Colección "Pérez Simón", llevan un robé a l'anglaise. También la mantilla y el tocado de la mujer del subyacente se parecen a los que llevan las ayas representadas en el cuadro La familia del Infante Don Luis, el mismo cuyos aderezos se plasman depositados sobre la bandeja que porta una de estas ayas, a la espera de que el peluquero decida colocárselo a Mª Teresa Vallabriga.

Precisamente, el tipo de traje que viste la mujer del retrato subyacente, así como la mantilla y el tocado fueron algunos de los elementos que permitieron saber la fecha aproximada de la creación de esta obra durante la primera fase del estudio. El robé a l'anglaise fue introducido en la moda española hacia 1782 para dejar de ser tendencia en 1785, aproximadamente, igual que el tocado de rosas y la mantilla a los que ya se ha hecho alusión. Otro aspecto que afianzó el año 1782 como el primero en el que fue posible la creación de este cuadro es que, si bien Goya comenzó a tener contacto con la clase noble en 1780, en 1781 estuvo trabajando en Zaragoza y no fue hasta 1782 cuando volvió a Madrid, donde se encontraba la Corte y, por consiguiente, donde tenía mayores probabilidades de trabajar para algún noble. Sin embargo, de ser cierto que $M^{a}$ Teresa de Vallabriga es la mujer del retrato pintado bajo el de Gaspar Melchor de Jovellanos, las cartas que Goya escribió a su amigo Zapater permitirían delimitar la fecha de ejecución de esa obra entre 1783 y 1784 , dado que, según consta en esa correspondencia, Goya trabajó por primera vez para el Infante Don Luis en el verano de 1783 y también en el de 1784, pero el siguiente año el Infante cayó enfermo y falleció.

\section{Agradecimientos}

Las autoras desean transmitir su agradecimiento a las personas e Instituciones que han colaborado en este estudio:

A D. Alfonso Muñoz, Subdirector del Instituto del Patrimonio Cultural de España y a D. Emilio Marcos, Ex Director del Museo de Bellas Artes de Asturias, por las facilidades ofrecidas para hacer posible la cooperación entre estas dos Instituciones. Del mismo modo, a Da Marián del Egido, Jefe del Área de Laboratorios del IPCE, por las gestiones realizadas con respecto a este trabajo. 
A las personas que participaron en la captación de la imagen radiográfica del retrato de Jovellanos de Goya, procedentes del Servicio de Estudios Físicos del IPCE, entre las cabe citar a D. Tomás Antelo, $D^{a}$ Carmen Vega y $D^{a}$ Miriam Bueso. Así mismo, a Da Ángeles Anaya, quien efectuó la digitalización y la posterior unión de las placas radiográficas de esta obra para obtener una imagen global de alta calidad y resolución.

A Da Rocío Bruquetas, del Servicio de Estudios Físicos del IPCE, por sus inestimables y desinteresadas aportaciones documentales, al igual que por el asesoramiento ofrecido en relación al texto.

A Da Marisa Gómez, del Laboratorio de Química del IPCE, por su objetividad, eficiencia y profesionalidad, demostradas en los análisis que ha realizado de las muestras del retrato de Jovellanos conservado en el Museo de Bellas Artes de Asturias.

A D. Rafael Serrano Rubio, historiador de Arte y a $D^{a} M^{a}$ Teresa Rodríguez Torres, farmacéutica e historiadora de Arte especializada en Goya, por su contribución en la identificación de la mujer de la radiografía.

A D Carmen Espinosa y a Da Amparo López, Conservadoras de la Fundación Lázaro Galdiano, por sus atenciones y orientación con respecto a la identidad de la mujer del retrato subyacente.

A Da Amalia Descalzo, Especialista en indumentaria, por brindar sus conocimientos y opinión acerca del tipo de vestido de la mujer.

A Da Teresa Caballero, Bibliotecaria del Museo de Bellas Artes de Asturias, por su colaboración en la localización de documentación.

A Da Lucía González Álvarez, licenciada en Filología Inglesa y profesora, por realizar la traducción del resumen de este trabajo al inglés.

\section{Notas}

[1] Según indica Carmen Garrido, el primero de los personajes retratados es José Álvarez de Toledo y Gonzaga, Marqués de Villafranca y sobre él, aparece representado Godoy, de cuerpo entero.

[2] Algunos estudiosos consideran que la persona que aparece montada a caballo bajo el retrato del Duque de Wellington es José Bonaparte, mientras que para otros se trataba de Godoy.

[3] Los resultados de los análisis de las muestras procedentes del retrato de Jovellanos conservado en el Museo de Bellas Artes de Asturias, efectuados por Da Marisa Gómez, técnico del Laboratorio de Química del Instituto del Patrimonio Cultural de España (IPCE), han permitido corroborar algunas de las hipótesis planteadas en la primera fase del estudio de esta obra, como puede ser la existencia de una capa de imprimación entre el retrato de Jovellanos y el subyacente (González-Fanjul; Gabaldón et Alba 2011: 166, 172). Estos análisis no han sido incluidos en el presente artículo, debido a que éste se ha centrado en conocer la identidad del personaje femenino de la composición subyacente y no en la técnica de ejecución de los dos retratos, si bien no se descarta hacerlos públicos en el futuro para completar el estudio desarrollado hasta ahora.

[4] El 9 de julio de 2011, el grupo de Teatro Odisea estrenó en el teatro Filarmónica de Oviedo Jovellanos, la pasión oculta, inspirada en los amores entre Jovellanos y Enarda.

[5] Propuesta realizada verbalmente por D. Rafael Serrano Rubio, historiador de arte, así como por Da María Teresa Rodríguez Torres, historiadora autora de libros especializados en Goya, como pueden 
ser Goya, Saturno y el saturnismo (Rodríguez, 1993) o Goya: entre sueños, chanzas y realidad (Rodríguez, 1996).

[6] Este título fue heredado por su hija, Da Teresa de Borbón y Vallabriga, pintada como "Condesa de Chinchón" en 1800 por Goya, ya casada con Godoy y embarazada de su primera hija.

\section{Bibliografía}

ÁGUEDA, M. et SALAS, X. (eds.). (1982). Francisco de Goya: cartas a Martín Zapater. Madrid: Turner.

ANSÓN, A. (1995). "Revisión crítica de las cartas escritas por Goya a su amigo Martín Zapater". Boletín del Museo e Instituto Camón Aznar. 59-60: 247-292.

Disponible en: http://155.210.60.69/InfoGoya/Repositorio/Partes/Anson1995_RevisionCriticaCartas.pdf [1609-2012]

ARNAIZ, J. M. et MONTERO, A. (1986). “Goya y el Infante Don Luis". Antiquaria. Marzo, no 27: 44-48.

ARNAIZ, J.M. (1987). “Goya joven, comentarios al hilo de la exposición”. Antiquaria. 37: 46-53.

BRAHAM, A. (1966). "Goya's Equestrian Portrait of the Duke of Wellington". Burlington Magazine. CVIII: 618621.

CALVO SERRALLER, F. et al. (2001). Goya. La imagen de la mujer. Madrid: Fundación Amigos del Museo del Prado y Caja Madrid.

CARDERERA Y SOLANO, V. (1996) Estudios sobre Goya (1835-1885). Ricardo Centellas Salamero (ed.). Zaragoza: Institución Fernando el Católico.

ESPAÑOL BOUCHÉ, L. (1999). Nuevos y viejos problemas en la Sucesión de la Corona Española. Madrid: Ediciones Hidalguía.

GARRIDO, C. (2003). "El retrato de la condesa de Chinchón: Estudio técnico", Boletín del Museo del Prado, t. XXI, n० 39: 44-55.

GASSIER, P. et WILSSON, J. (1970). Vie et oeuvre de Francisco de Goya. Fribourg/Suisse: Office du libre. Ed. en español, (1974) Vida y obra de Francisco de Goya: reproducción de su obra completa, pinturas, dibujos y grabados. Barcelona: Juventud.

GONZÁLEZ-FANJUL, C.; GABALDÓN, A. et ALBA, T. (2011). "Una imagen subyacente en el retrato de Jovellanos de Goya". En Ciencia y Arte III, (Valencia, 17 y 18 de Noviembre de 2010). Madrid: Ministerio de Cultura, Subdirección General de Instituto del Patrimonio Cultural de España: 159-173.

GONZÁLEZ SANTOS, J. (1992). "Jovellanos por Goya. Precisiones históricas e iconográficas sobre dos conocidos retratos". Boletín del Museo del Prado. Tomo XIII, n 31: 45-56.

GOYA, F. de; CANELLAS LÓPEZ, Á. (ed.) (1981). Diplomatario de Francisco de Goya. Zaragoza: Institución Fernando el Católico, no 826.

Disponible en: http://ifc.dpz.es/recursos/publicaciones/10/54/_ebook.pdf [16-07-2012]

GUDIOL, J. (1970). Goya. 1746-1828. V. II. Barcelona: Polígrafa.

JUNQUERA Y MATO, J. et Patio de la Infanta. (1996). Goya y el Infante Don Luis de Borbón: homenaje a la "Infanta Doña María Teresa de Vallabriga": del 14 de octubre al 30 de diciembre de 1996. Zaragoza: Patio de la Infanta. 
LEIRA SÁNCHEZ, A. (2007). “La moda en España durante el siglo XVIII”. Indumenta, №: 87-94.

MARQUÉS DE LOZOYA (1946). Boletín de la Real Academia de la Historia. Conmemorativo del Bicentenario del Nacimiento de D. Francisco de Goya. Madrid: Viuda de Estanislao Maestre.

MARTínEZ RIPOLL, A. (1979). “Un retrato alegórico de Godoy visto con Rx, por Goya”. Goya. №148-150.: 294299

MATHERON, L. (1858). Goya. París: Schulz et Thuillié.

MENA MARQUÉS, M. y MAURER, G. (2006). La duquesa de Alba, "musa" de Goya: el mito y la historia. Madrid: Museo del Prado.

MENA MARQUÉS, M. (2008). "La Condesa de Chinchón". En MENA MARQUÉS, M. et al. Goya en tiempos de guerra. Madrid: Museo Nacional del Prado: 188-190.

MONTERO, A. (1989). “La pinacoteca de Doña María Teresa de Vallabriga y Rozas”. Antiquaria. No65: 34-43.

RIBEIRO, A. (2001). "La moda femenina en los retratos de Goya". En CALVO SERRALLER et al. Goya. La imagen de la mujer. Madrid: Fundación Amigos del Museo del Prado y Caja Madrid: 103-116.

RODRÍGUEZ, T. (1993). Goya, Saturno y saturnismo. Madrid:T. Rodríguez.

RODRÍGUEZ, T. (1996). Goya: entre sueños, chanzas y realidad. Madrid: Ars Magna.

SALAS, X. de (1980). Goya. Barcelona: Compañía internacional editora, S.A.

SESEÑA, N. (2004). Goya y las Mujeres. Madrid: Taurus.

TORRALBA SORIANO, F. (1996). Realidad e imagen: Goya, 1746-1828. Zragoza: Gobierno de Aragón.

VALVERDE, J. (1989). "Goya y Broccherini en la Corte de Don Luis de Borbón". En El arte en las Cortes europeas del siglo XVIII: Madrid, Aranjuez, 27-29 de abril de 1987. Madrid: Servicio de documentación y publicaciones de la Comunidad Autónoma de Madrid: 793-802.

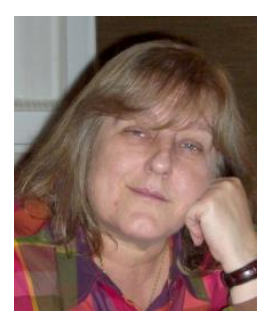

\section{Clara González-Fanjul}

clarafanjul@yahoo.es

Clara González-Fanjul, Jefe del Departamento de Conservación y Restauración del Museo de Bellas Artes de Asturias. Restauró los fondos de la colección con la que fue creado este museo, así como las obras procedentes de la Colección Masaveu como pago de impuestos de sucesión. También ha impartido cursos, ha escrito diversos artículos y pronunciado conferencias sobre temas relacionados con el arte y la profesión del Conservador-Restaurador. 


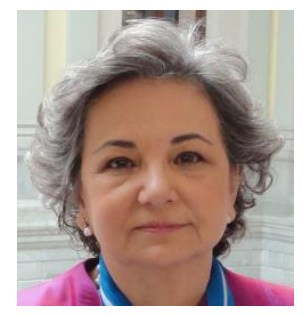

\section{Araceli Gabaldón}

aragabaldon@yahoo.es

Araceli Gabaldón, licenciada en Ciencias Físicas. Ha desarrollado su trabajo como supervisora de la Instalación Radiactiva del Instituto del Patrimonio Cultural de España (IPCE), Área de Laboratorios, Estudios Físicos. Ha promovido el desarrollo de la reflectografía y de la radiografía junto a Tomás Antelo, obteniendo muchas mejoras tanto en la captación de imágenes como en la unión y calidad de las mismas. Ha hecho numerosos trabajos sobre Berruguete, Gallego y otros pintores. Se debe destacar entre ellos la captación de la radiográfica de varios retablos de gran tamaño así como del Guernica de Picasso en una sola toma.

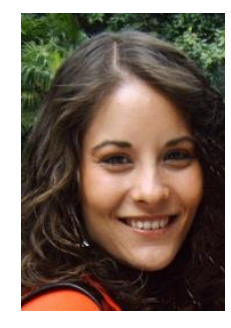

\section{Tamara Alba}

tamarafanjul@gmail.com

Tamara Alba, licenciada en Bellas Artes (especialidad de Conservación-Restauración). Doctoranda de la facultad de Bellas Artes de la Universidad Complutense de Madrid (UCM). Está en posesión del Diploma de Estudios Avanzados (DEA) y, actualmente, está realizando su tesis doctoral en el marco del programa "Conservación-Restauración del Patrimonio Histórico-Artístico". Ha sido colaboradora honorífica del Departamento de Pintura-Restauración de la facultad de Bellas Artes de la UCM y becaria de esta facultad, como miembro del Grupo de Trabajo "Técnicas Ópticas de Análisis Aplicadas al Patrimonio". Así mismo, ha trabajado para el IPCE en el Servicio de Estudios Físicos, colaborando en el estudio de dos retablos. 